\title{
Biologics, biosilimars, and biobetters: different terms or different drugs?
}

\author{
Ashish Sharma $^{1} \cdot$ Nilesh Kumar $^{1} \cdot$ Baruch D. Kuppermann ${ }^{2} \cdot$ Francesco Bandello $^{3}$ - Anat Loewenstein ${ }^{4}$
}

Received: 19 February 2019 / Accepted: 22 February 2019 / Published online: 7 March 2019

(c) The Royal College of Ophthalmologists 2019

Biologics since their inception have revolutionised the treatment protocol by directly targeting the molecular pathophysiology of many diseases which were earlier thought to be untreatable. But their development was restricted due to a demanding research and development (R\&D) process, and low conversion rate from development to commercialisation. The biologics were thus comparatively fewer in numbers and had a premium price tag. This restricted their usage in low income strata. This problem was answered by the development of biosimilars, the biologics which are similar in structure, efficacy, and safety to the reference molecules, are well regulated and reduce the cost of treatment upto 25\% [1]. Biosimilars though have the potential to be market disruptors for affordability and wider availability; they are restricted in their pharmacological action due to their inherent "similarity" with the biologics. Biosimilars are ought to be similar to biologics in their target protein, their formulation, dosing and administration. With advent of better manufacturing techniques, purification processes, novel administration procedures it is prudent that the biologics become better.

Mr. G.V. Prasad, CEO of Dr. Reddy Laboratories, India in a conference on Biologics in Mumbai in 2007 introduced the term 'Biobetters' for the first time. Since

$\triangle$ Ashish Sharma

drashish79@hotmail.com

1 Department of Vitreoretina, Lotus Eye Hospital and Institute, Coimbatore, TN, India

2 Gavin Herbert Eye Institute, University of California, Irvine, Irvine, CA, USA

3 Department of Ophthalmology, University Vita-Salute, Scientific Institute San Raffaele, Milano, Italy

4 Division of Ophthalmology, Tel Aviv Sourasky Medical Center and Sackler Faculty of Medicine, Tel Aviv University, Tel Aviv, Israel then it has been widely used but still is not a defined term. In essence, it means a biologic which is better or superior to the reference molecule in one or more parameter while having similar target $[2,3]$. They can be having a different amino acid sequence, chemical modification, protein folding, humanization process, purification process which can lead to a better formulation and dosing regimen, provide a better shelf life, or give a superior pharmacological effect as compared to the reference biologics $[4,5]$.

\section{Current regulatory pathway}

Biosimilars caught the attention of market regulators early in their inception and thus a detailed guideline for regulatory approval is now in place for majority of markets across the globe. Majority of these guidelines were put in place to ensure the quality of biosimilars as they won't become generics of the reference molecule, as happened with generics of low molecular weight drugs. Concept of better formulation is not applicable on low molecular weight drugs, and probably so the biobetters have not gained as much traction as this only applies to biologics. Similar to low molecular weight drugs where the next generation drug is considered as a new drug and has to undergo a full application process, biobetters too are considered as an investigational new drug (IND) and have to prove their safety and efficacy in all the indications for which they want approval [6-8]. Thus, biobetters can be considered as next generation biologics too.

\section{Who can benefit from biobetter?}

Biopharmaceutical market is lucrative with exponential growth potential. Thus, every drug manufacturer wants to have them on its portfolio. But investing in an "Innovator molecule" involves risk due to huge R\&D cost involved. 
At 1/10th of the cost, these manufacturers can formulate a biosimilar molecule [9]. But there is hesitation among the medical fraternity, where still many consider this to be generic drugs and use it on patients who can't afford the innovator molecule. This inertia can be overcome by understanding and investing into biobetters.

Biobetters are more resource demanding during R\&D, but with proven target at hand and good efficacy of the reference biologics, there is less likelihood of these molecules to fail to reach production. The $R \& D$ phase is also significantly shorter compared to an innovator molecule [8]. As these drugs are considered to be IND, they do not have to wait for patents and market exclusivity to expire and hence give returns to the manufacturers better than biosimilars. As they have similarity to the reference biologic, it is difficult for them to get patented but they can gain market exclusivity. This can be utilised by the innovators to protect their market share by bringing in new manufacturing process for their molecules [10, 11]. This can also be used by the competitors to gain market exclusivity of a better compound before expiry of the innovator molecule [12].

Genentech is working on a port-based delivery system on their innovator molecule Ranibizumab which aims to better the delivery of drug, increase efficacy and reduce the treatment cost [13]. Ildong pharmaceuticals simultaneously are working on Ranibizumab based biobetter which aims to increase efficacy and eliminate the Ranibizumab resistance in patients with age-related macular degeneration (AMD) [14]. Alteogen, a Korea based drug manufacturer became the first company to patent a biosimilar to Regeneron's aflibercept formulation Eylea. This drug, though is proposed as biosimilar but has better shelf life and increased heat resistance due to different manufacturing process $[15,16]$.

As biobetters are more efficient than the biosimilars or reference molecule, they can demand a price premium, in contrast to biosimilars that have to be price sensitive as they are not offering anything new or better to the patient. This premium price can be negated by reduced dosing, better half-life of the drug, and longer shelf life and are anticipated to lower the overall cost of treatment $[5,17]$.

\section{Conclusion}

Biobetters are poised to be the next generation of biologics with various advantages on horizon. Their development should be encouraged by providing relaxation in the norms for astronomical amount of trials that is usually required for an IND as they have a proven target and a reference molecule with known safety and efficacy. With them being considered as IND, innovators also get a chance to retain their market share which was not possible for biosimilars. Competitors too will try to introduce the biobetter molecules and will try to keep the cost lower than innovator's biobetter, making them price sensitive. By virtue of their better formulation and dosing schedule, they can reduce the economic burden these diseases are indenting currently on the society.

\section{Compliance with ethical standards}

Conflict of interest The authors declare that they have no conflict of interest.

Publisher's note: Springer Nature remains neutral with regard to jurisdictional claims in published maps and institutional affiliations.

\section{References}

1. Grabowski H, Guha R, Salgado M. Biosimilar competition: lessons from Europe. Nat Rev Drug Discov. 2014;13:99-100.

2. DePalma A Will biobetters beat biologics? I eyeforpharma. 2011. https://social.eyeforpharma.com/commercial/will-biobetters-beatbiologics. Accessed 5 Feb 2019.

3. Weise M, Bielsky M-C, De Smet K, Ehmann F, Ekman N, Narayanan $\mathrm{G}$, et al. Biosimilars-why terminology matters. Nat Biotechnol. 2011;29:690-3.

4. Dinwoodie N. Biobetters and the future biologics market. BioPharm International. 2011. http://www.biopharminternational.com/ biobetters-and-future-biologics-market. Accessed 5 Feb 2019.

5. Strohl WR. Fusion proteins for half-life extension of biologics as a strategy to make biobetters. BioDrugs. 2015;29:215-39.

6. Andrei S, Valeanu L, Chirvasuta R, Stefan MG. New FDA approved antibacterial drugs: 2015-2017. Discoveries. 2018; 6:e81.

7. de Mora F. Biosimilar: what it is not: biosimilar concept. Br J Clin Pharmacol. 2015;80:949-56.

8. Kesik-Brodacka M. Progress in biopharmaceutical development: Progress in Biopharmaceutical Development. Biotechno1ApplBiochem. 2018;65:306-22.

9. Sharma A, Reddy P, Kuppermann BD, Bandello F, Loewenstein A. Biosimilars in ophthalmology: is there a big change on the horizon? Clin Ophthalmol. 2018;12:2137-43.

10. LoRusso PM, Weiss D, Guardino E, Girish S, Sliwkowski MX. Trastuzumab Emtansine: A Unique Antibody-Drug Conjugate in Development for Human Epidermal Growth Factor Receptor 2Positive Cancer. Clin Cancer Res. 2011;17:6437-47.

11. Verma S, Miles D, Gianni L, Krop IE, Welslau M, Baselga J, et al. Trastuzumab Emtansine for HER2-Positive Advanced Breast Cancer. N Engl J Med. 2012;367:1783-91.

12. Anour R. Biosimilars versus 'biobetters'-a regulator's perspective. Generics Biosimilars Initiat J. 2014;3:166-7.

13. Sharma A, Bandello F, Kuppermann BD, Makan D Retinal Physician - Wet AMD in 2018: Drugs in Development. Retinal Physician. https://www.retinalphysician.com/issues/2018/april2018/wet-amd-in-2018-drugs-in-development. Accessed 11 Feb 2019.

14. Ildong Pharmaceutical. https://mobile.ildong.com/eng/static/rnd/ RD_004.id.

15. Eye on Pharma: Alteogen to File IND for Proposed Aflibercept Biosimilar. Center for Biosimilars. https://www.centerforbiosimila rs.com/news/eye-on-pharma-alteogen-to-file-ind-for-proposed-a flibercept-biosimilar. Accessed 11 Feb 2019. 
16. alteogen. Alteogen Inc. Becomes First Mover for Eylea Biosimilar with securing global competitiveness by registering patent. http://a lteogen.cafe24.com/?kboard_content_redirect $=287$. Accessed 11 Feb 2019.
17. Zalevsky J, Chamberlain AK, Horton HM, Karki S, Leung IWL, Sproule TJ, et al. Enhanced antibody half-life improves in vivo activity. Nat Biotechnol. 2010;28:157-9. 